\title{
Nano-Sized Elements in Electrochemical Biosensors
}

\author{
Joanna Cabaj, Jadwiga Sołoducho* \\ Faculty of Chemistry, Wroclaw University of Technology, Wrocław, Poland \\ Email: joanna.cabaj@pwr.edu.pl, ${ }^{*}$ jadwiga.soloducho@pwr.edu.pl
}

Received 14 June 2014; revised 16 July 2014; accepted 30 July 2014

Copyright (C) 2014 by authors and Scientific Research Publishing Inc.

This work is licensed under the Creative Commons Attribution International License (CC BY). http://creativecommons.org/licenses/by/4.0/

(c) (i) Open Access

\section{Abstract}

The emerging nanotechnology has opened novel opportunities to explore analytical applications of the fabricated nano-sized materials. Recent advances in nano-biotechnology have made it possible to realize a variety of enzyme electrodes suitable for sensing application. In coating miniaturized electrodes with biocatalysts, undoubtedly the most of the potential deposition processes suffer from the difficulty in depositing process and reproducible coatings of the active enzyme on the miniature transducer element. The promising prospects can concern to the obtaining of thin protein layers by using, i.e. electrochemical deposition, electrophoretic deposition as well as monolayer methods (Langmuir-Blodgett procedure, Layer-by-Layer-LbL). Many aspects dealing with deposition of enzyme by techniques employing electric field are considered, including surface charge of enzyme, and its migration under applied electric filed. The using of nanoscale materials (i.e. nanoparticles, nanowires, nanorods) for electrochemical biosensing has seen also explosive increase in recent years following the discovery of nanotubes. These structures offer a promise in the development of biosensing, facilitating the great improvement of the selectivity and sensitivity of the current methods. Finally, the perspectives in the further exploration of nanoscaled sensors are discussed.

\section{Keywords}

Enzymes, Immobilization, Nanobiosensors, Nanoparticles

\section{Introduction}

To date, there is an increasing necessity for mighty analytical tools with high sensitivity, fast response, selectivity, accuracy and low cost of production/operation. Notably, biosensors have found comprehensive adoption in

${ }^{*}$ Corresponding author. 
the area of environmental control as well as pharmaceutics and medical diagnostics. Consequently, the main objective in biosensors design is the sufficient development of a biosurface, firmly sensitive and selective for a respective analyte, which may be able to generate measurable signals coupled to an adequate transducer.

Thus, many groups of researchers tend also to combine nanoparticles into the materials used for biosensors in order to improve the sensitivity of the system in potential sensing applications. Most recent studies show that biosensors composed with nanoparticles do take on rapid, simple, and accurate measurements, which offers exciting new opportunities for the development of biosensor capabilities. Owing to the emerging roles that nanoparticles are playing in the improvement of biosensors in recent years, it is necessary and meaningful for us to investigate the researches of nanoparticle-based biosensors from the point of view of management of technology. As a vital part of management of technology, grasping the latest development of technology and identifying the emerging characters can help us get competitive advantages in the future.

Several kinds of nanoparticles, including metal nanoparticles, oxide nanoparticles, semiconductor nanoparticles, and even nanodimensional conducting polymers have been used in biosensing systems. Owing to these unique properties, different kinds of nanoparticles always play different roles in different sensing systems. Generally, metal nanoparticles are always used as elements of "electronic wires". Oxide nanoparticles are often applied to immobilize biomolecules, while semiconductor nanoparticles are often used as labels or tracers [1].

The development of high performance and reliable miniaturized enzyme electrodes is a crucial objective worth pursuing in the nanosized biotechnology area. The miniaturization bids numerous advantages [2]. Miniaturized enzyme electrodes are useful in analysis of small sample volumes, hence practical if only small amounts of biological fluids are provided or, waste saving if larger quantities are available. These small systems can be also integrated into new technologies like microarray sensor or microfluidic systems. When used in vivo, miniaturized systems create less damage of the tissues and hence quick healing.

Certainly, there are several methods (i.e. Langmuir-Blodgett techniques, LbL) with which enzymes can be deposited including but not limited to entrapment and crosslinking [3]. But an important problem in the application of enzymatic proteins for the development of miniaturized electrodes is the difficulty in depositing uniform and reproducible layer coatings of enzymes on the transducer [4].

Electrochemical and electrophoretic deposition are offered as techniques, which can employ electric field to produce apparently uniform and reproducible layer coatings of biocatalysts over very small areas. Electrochemical deposition is known for several decades, but by the contrast electrophoretic deposition is rather recent technique [5]. However, further development work needs to be done according to optimize the parameters for a broader use of especially in the fabrication of miniaturized enzyme systems [4].

\section{Immobilization of Enzymes in Miniaturized Systems}

\subsection{Electrochemical Deposition}

A study of literature indicates that electrochemical deposition is one of the most techniques employed for enzyme immobilization, because of simple, cost effective apparatus. Electrochemical deposition can be employed to drive enzymes alone to deposit on the support, as well as with other components including i.e. collagen [6], noble metal salts (Pt, Pd) [7], monomers such as pyrrole, 1, 3-diaminobenzene [8], some redox mediators (i.e. Prussian blue) or redox centers [9], nanomaterials like carbon nanotubes and metal nanoparticles [10]. The final goal of all these efforts is to fabricate enzyme electrodes with appropriate characteristics in terms of preserved activity, enhanced kinetics and stability to fit with the specific application.

Generally, the activity of enzyme electrode prepared by electrochemical deposition depends primarily on thickness of the enzyme layers [11].

The latter yields deposition of thin enzyme coatings because only enzymes present nearby vicinity of the electrode surface precipitate. Matsumoto et al. [12] observed that only few tens of nanometer are produced. The thickness of the enzyme coating can be increased to reach much thicker layers if i.e. a surfactant is added to enzyme solution prior deposition.

According to kinetics, it was observed, that enzymes deposited under electrochemical deposition may or may not keep similar kinetics as nativeproteins [13] [14]. This fact depends on the environment of the deposited enzyme coating and presence of other components. In case of stability, enzyme electrodes produced by electrochemical technique have usually moderate stabilities [4]. 


\subsection{Electrophoretic Deposition}

Electrophoretic deposition is carried on from low conductivity aqueous solutions/suspensions (Figure 1). The technique requires high strength electric fields, which can reach several hundreds of volts to move the charged biocatalysts from bulk of the solution to the electrode. Both parameters of elevated zeta potential and high strength electric field yield significant migration of enzymatic proteins under electrophoretic deposition [4]. As a result, more enzymes reach the surface of the electrode and precipitate to form thick-deposited coatings [15]. It is weighty, that when high strength electric fields are employed in electrophoretic deposition, continuous direct current can no longer be utilized because it can induce heat and extensive water electrolysis [4]. This situation causes changes in temperature and $\mathrm{pH}$ in the environment of electrodes which maylowered the activity of the protein [16]. To avoid the problem it is possible to apply pulsed direct current and alternating current [4].

Alternating current is no fixed anode or cathode but the polarization of each electrode changes continuously between the positive and negative signs. Due to the fact, that a negatively charged enzyme is subjected to asymmetrical alternating current signal, it should only oscillate in one location because the migration achieved during the first half cycle when one of electrodes is positively charged should be neutralized during the second half process when the other electrode becomes positively charged [4]. According to that, the migration of charged enzyme under symmetrical signals is zero. In results, only thin enzyme coatings can be deposited [5] [17]. Whereas, under unsymmetrical alternating current field is applied to negatively charged protein, large amount of enzymes accumulate nearby the surface of electrode and the enzymes precipitate to yield thick deposited layers. Furthermore, because alternating current fields generate the minimum of water electrolysis as well as heat, the maximum enzymes activity could be preserved after deposition [5] [17]. There is found a several enzymes (i.e. glucose oxidase, peroxidase), which have been successfully immobilized by this method [4] [5] [17].

\subsection{Thin Layer Methods}

Adsorption of organic molecules on solid conducting supports to produce thin nanostructured films are one of the most employed architectures and represents an important approach in the field of nano-manipulation. Langmuir-Blodgett (LB) technique promotes a high control of the physical and chemical properties of nanostructured organic films and plays an important role in the production of miniaturized devices applicable as platforms for enzyme immobilization [18].

Other pathways to prepare platforms based on nanomaterials, aiming the fabrication of electrochemical biosensors are dispersion in solvents, adsorption (e.g. LbL), formation of covalent bonding.

As well, the utilization of hybrid organic/inorganic thin films can, in a simple manner, be employed in solid conductor electrodes. The possibility to incorporate hybrids containing nanostructured materials for enhance electrochemical properties makes these techniques much attractive in the field of bionanoelectrochemistry [19] [20].



Figure 1. Electrophoretic coating. 
The aim is to preserve the native enzyme molecular conformation and to arrange it in a suitable position for the molecular recognizing of an external molecule of a solution put on contact with the Langmuir-Blodgett device. As defended in a review by Girard-Egrot [21], the successful incorporation of enzymes on a preformed Langmuir monolayer depends strongly on the methodology employed. The most one commonly used is the adsorption of the enzyme from the subphase, avoiding direct adsorption of the macromolecule present at the water surface. This strategy was used to produce electrochemical sensors containing i.e. phytic acid [22], horseradish peroxidase [23], hemoblogin [24], and urease [25], tyrosinase [26], to detect a diversity of substances such as including phytic acid, hydrogen peroxide, glucose, choline, urea, and phenols.

In these types of sensors the sensor sensitization can be achieved by i.e. an amphiphilic heterocyclic semiconducting structures admixed into the film [27] or other, more sophisticated architectures have been developed in order to enhance the performance of LB-based enzyme electrochemical sensors. For instance, Sun et al. [28] used pyriduylthio-modified carbon nanotubes as Langmuir-Blodgett films to support hydrogenase added in a subsequent adsorption from solution.

Alternatively, a modern concept of self-assembly was introduced by Decher and co-workers [29] [30] at 90 decade as a low-cost and simple method to obtain nanostructured thin films under controlled conditions ( $\mathrm{pH}$, temperature, polyelectrolyte concentration, ionic strength, etc.). For this purpose, a large variety of materials for electrochemical sensing and biosensing can be obtained [31]-[33]. Basically, the processes of film fabrication by LbL technique (Figure 2) is governed by the adsorption of organic polyelectrolytes with opposite charges present on their molecular structure, in such a way that film roughness, thickness, porosity and morphology can be controlled at molecular level [34]. Important advantage in the use of LbL technique to construct biosensors is the possibility to incorporate organic/inorganic composite materials that contributes for the maximization of the biodevices electrochemical signal [35]. Also, it is important to emphasize that most hybrids based on nanomaterials has been utilized to detect electrochemical signal from biochemical reactions.

Proteins have also been used in LbL method to construct alternate multilayer of ceramic nanotubes (halloysite), spherical particles leading to an array of new ordered nanoparticles-tubules, which were applied to load co-enzymes (NAD) for the development of enzymatic nanoreactors. Decher and co-workers [36] also reported the use of protein/polyelectrolyte hybrid films via specific recognition. One of the main challenges is to maintain the integrity of the native protein structure to promote their utilization for technological applications.

Ram and co-workers [37] reported the utilization of LbL technique to produce nanostructured films of poly(ethylene imine) and poly(sodium polystyrene sulfonate), cholesterol oxidase and cholesterol esterase. The strong stability of multilayer films was also evaluated and contributes directly for the electrochemical properties of the film warranting the glucose oxidase immobilized on solid conductor supports remained active on the electrode surface.

\section{Nanomaterials Used in Electrochemical Biosensors}

Nanomaterials has enabled the development of ultrasensitive electrochemical biosensors due to their high surface area, advantageous electronic properties and electrocatalytic activity as well as proper biocompatibility induced by nanometer size. Nanoscale materials have been used to obtain direct wiring of enzymes to electrode surface, to promote electrochemical reaction, to impose barcode for biomaterials and to amplify signal of biorecognition event. The resulting electrochemical nanobiosensors have been applied in areas of i.e. cancer diagnostics and detection of infectious organisms.
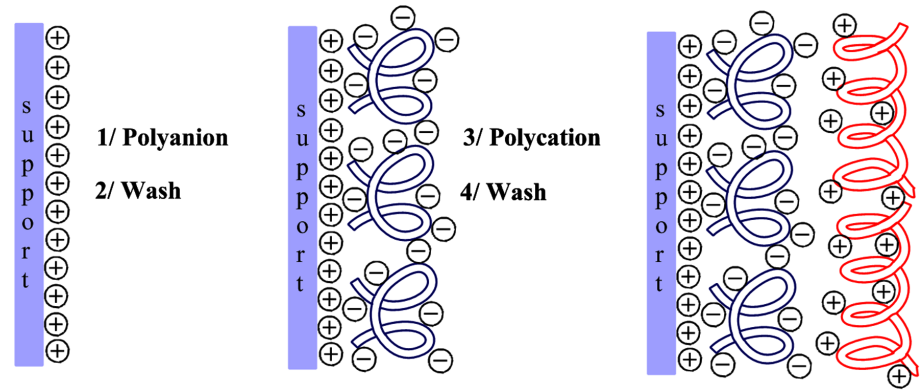

Figure 2. LbL technique. 
The application of nanometer size materials including nanoparticles, nanowire, nanoneedle, nanotube etc., for electrochemical biosensing have seen explosive growth in the last few years, since the report the detection of NADH using carbon nanotube-modified electrodes by the Wang and co-workers [38] as well as the first use of gold nanoparticles in electrochemical immunosensors [39].

\subsection{Nanowires in Biosensors}

Nanowires belong to a growing family of nano-objects, which also includes nanotubes, nanoparticles, nanorods, etc. Nanowires can serve as electrodes or interconnects between micro- and nanoelectronic devices. Furthermore, their dimensions are on the same scale as biomolecules, which unveils exciting possibilities for their interaction with biological species such as enzymes [40].

Most of them are silicon-based semiconductors, conducting polymers, and various oxides. Occasionally, also metallic nanowires have also been used in biological sensing devices. The nanoscale wire material may be adapted for the relevant functionality of the device. Nanosized wires possess several curious merits such as unusual sensitivity in determining surface bio-affects (Figure 3) [41]. The electronically switchable features of semiconducting nanoscale wires permit for immediate electrochemical detection. Although the subject of nanowired biosensors was reviewed to this moment [42].

\subsection{Nanotube-Based Biosensor}

Carbon nanotubes (CNTs) because of their unique mechanical and electrical properties are one of the most widely studied nanomaterials [43]. CNTs are an attractive material in bio-electrochemistry with the dual benefits of their electrical conductivity and the nanotopography they provide in electrode structures. The latter property maximises the possibility of bringing CNTs into close proximity with proteins and enables CNTs to act as one dimensional nanochannels for electron transfer in proteins [44] [45].

Molecules with specific recognition sites must be tethered onto the nanotube surface to facilitate a predictable alteration in nanotube electronics, triggered by the binding of target analyte molecules. CNTs are receptive to functionalization either by oxidative processes that form reactive groups, or through direct covalent/non-covalent modification of the sidewalls. Covalent attachment involves direct attachment of the functionality to the CNTs via the formation of chemical bonds, altering carbon-carbon bonds from $\mathrm{sp}^{2}$ to $\mathrm{sp}^{3}$ structure leading to a loss of conjugation and a subsequent change in electronic properties [44]. Non-covalent attachment involves CNT-molecule interactions involving electrostatic, van der Waals and/or hydrophobic interactions and preserves the $\mathrm{sp}^{2}$ structures and therefore, electronic properties. Moreover, the nature of non-covalent attachment can result in denaturation of the protein [44].

The natural affinity of protein hydrophobic domains toward carbon nanotubes allows for non-covalent functionalization of such biomolecules. Good electrochemical communication between multi-walled carbon nanotubes and redox proteins have been observed both at the protein surface in the case of horse radish peroxidase [46], cytochrome C [47] and azurin [48], and deep within the protein macrostructure e.g. glucose oxidase [49].

There was reported also how ferritin protein was non-covalently immobilized onto single-wall nanotube (SWNT) bundles [50]. Ferritin dispersed the SWNTs well in solution, resulting in a smaller SWNT bundle size, but the protein have to be in large excess to achieve this. Such adsorption/immobilization of proteins may result in deformation of the protein tertiary structure to achieve $\pi$-stacking along the nanotube walls. In contrast, use of

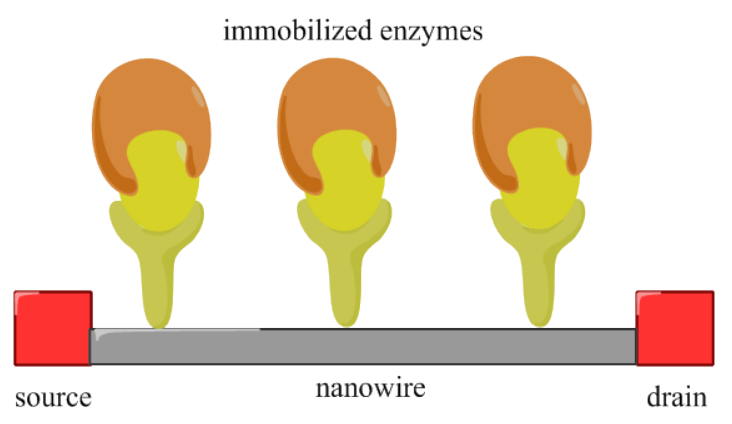

Figure 3. Simplified scheme of nanowired biosensor. 
the bifunctional linker, pyrenebutanoic acid succinimide ester, was reported by Dai and co-workers to immobileize proteins on SWNT surfaces [51].

CNT and glucose oxidase were also incorporated in paste electrodes using oil as binder for glucose biosensing [52]. However, one of the main disadvantages of paste electrodes is their poor mechanical properties. More rigid carbon nanotube biosensors were constructed by incorporating carbon nanotubes and glucose oxidase in epoxy matrix [53] [54]. Screen-printed CNT sensors, based on thick-film fabrication, are mechanically stable with good resistance to mechanical abrasion and they offer possibility of large-scale mass production of highly reproducible low-cost electrochemical biosensors [55]. CNT matrix also allows easy incorporation of enzyme in screen-printed electrode, as it was demonstrated on example of horseradish peroxidase in connection to multiwall carbon nanotube (MWCNT) and polysulfone binder, Figure 4 [56]. It was found that the enzyme immobilized in the carbon nanotube/polysulfone biocomposite keeps its activity with a very low diffusion barrier [57].

A convenient way to prepare biosensor is to coat carbon nanotube with one or multiple layers of enzyme by layer-by-layer process [58] [59]. Glucose oxidase can be immobilized on the negatively charged carbon nanotube surface by alternatively assembling a cationic poly (diallyldimethylammonium) chloride layer and enzyme layer. The sandwich-like layer structure formed by self-assembly technique provided an environment to keep the bioactivity of glucose oxidase and it prevented enzyme molecule leakage. The strong electrocatalytic activity toward hydrogen peroxide of the fabricated modified electrode indicated that the polyelectrolyte-protein film did not affect the electrocatalytic properties of CNT, enabling sensitive determination of glucose.

By using the LbL method, homogeneous and stable choline oxidase/polyaniline/MWCNT biosensor for choline detection was prepared [60]. Employing similar approach, glucose nanobiosensor was prepared by forming bilayer of the polyelectrolytes: poly(diallyldimethylammonium) chloride and poly(sodium 4-styrenesulfonate) on a 3-mercapto-1-propanesulfonic acid-modified gold electrode and subsequent consecutive LbL addition of multiwall carbon nanotubes wrapped by positively charged poly(diallyldimethylammonium) chloride and negatively charged glucose oxidase onto the poly (sodium 4-styrenesulfonate)-terminated bilayer [61].

Single-wall carbon nanotubes were employed as long-range wires connecting surface of electrode with redox centre of enzyme [62] [63]. Yu et al. [62] attached enzymes covalently onto the ends of vertically oriented single-wall carbon nanotube (SWCNT) forest arrays, which were used as nanoelectrodes. Authors suggested that the branched systems in the nanotube forest behaved electrically similar to a metal, conducting electrons from the external circuit to the redox sites of the enzymes. In other work, SWCNT was covalently linked to gold electrode surface and to glucose oxidase redox centre [63] [64].

\subsection{Silicon-Based Nanobiosensor}

Porous silicon is a useful nanosensor material. By measuring the change of the optical properties of porous silicon when a species is bound to its surface, the concentration of the species to be detected can be determined. Silicon nanowire based field field-effect transistors (FETs) have also been configured as sensors for the detection of chemical and biological species. The conductance of nanowires will change in response to the binding of chemical and biological species on the nanowire surface; that is, molecular or macromolecular species gate the FET and thereby change the conductance [65]. Amine- and oxide-functionalized SiNWs exhibit pH-dependent

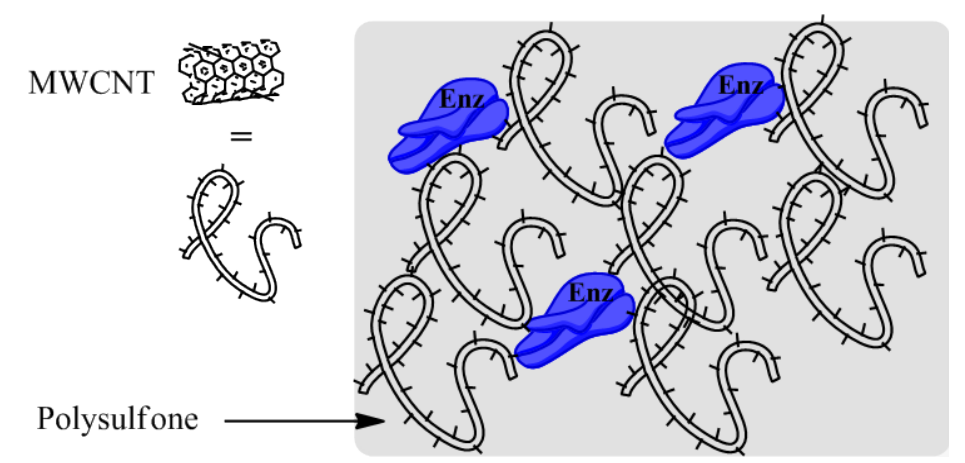

Figure 4. Schematic drawing of structure of horseradish peroxidase/MWCNT/ polysulfone composite. 
conductance that is linear over a large dynamic range and can be related to the change in surface charge during protonation and deprotonation processes. For example, biotin-modified SiNWs were used to detect streptavidin down to picomolar concentration range. Antigen-functionalized SiNWs showed reversible antibody binding and concentration-dependent detection in real time. There is believed that the small size and capability of these semiconductor nanowires for sensitive, label-free, real-time detection of a wide range of chemical and biological species could be exploited in array-based screening and in vivo diagnostics [65]. Lee and co-workers fabricated a series of sensors for gas, chemical, and bioanalytical applications using a bundle of silicon nanowires or nanowires films [66]-[68]. The sensor made by a bundle of HF-etched silicon nanowires exhibits a fast response and highly sensitive and reversible changes of the electrical resistance upon exposure to ammonia gas and water vapour [66]. Strands of aligned SiNWs with lengths over $2 \mathrm{~mm}$ and diameters of $35 \mathrm{~nm}$ were used to fabricate a multiwire strand of SiNWs into an electrode for cyclic voltammetric detection of bovine serum albumin [67].

A few cautionary notes are warranted here. First, for any nanosensor to be viable, it must have high sensitivity and selectivity, as well as good reliability in terms of stability and reproducibility. In particular, the sensing nanomaterial, which is crucial in the nanodevice design, must have reproducibility, long-term stability and high sensitivity. In this context, nanosensors or SiNW-FETs based on SiNWs are problematic due to the instability of H-terminated SiNWs in water and some organic solvents, especially in the $\mathrm{pH}$ range of 4 - 10 [69]. Oxide-passivated or surface-functionalized SiNWs are relatively more stable, though their long-term stability in water or other solutions. For example, for nanodevices based on electrochemical principles, it has been pointed out that the detection of binding of molecules, charged or neutral, to the surface of $\mathrm{SiO}_{2}$ by direct measurement of conductivity or electric field effect is not possible [69] [70].

\subsection{Gold Nanoparticles in Biosensing}

Metal nanoparticles have attracted a great amount of interest in chemical and biochemical sensing, where the considerable enhancement in the measured activity could be beneficially applied to the design of ultrasensitive transducer surfaces.

The enhanced reactivity of metallic nanoparticles can be attributed to the high surface area to volume ratio that results in an increase in the surface atom distribution, coupled with the property that these surface atoms have the highest reactivity because of the smaller number of atom neighbours [71].

In this context, gold nanoparticles (GNPs) have been studied extensively because they have high biocompatibility, good conductivity and satisfactory catalytic activity; this range of properties are particularly useful for the application of GNPs in the construction of electrochemical biosensors [72] [73].

In example, a metal nanoparticle-based electrochemical magnetic immunosensor was developed by using magnetic beads and gold nanoparticle labels [68]. Anti-IgG antibody-modified magneticbeads were attached to a carbon paste transducer surface by magnet that was fixed inside the sensor. Gold nanoparticle labels were capsulated to the surface of magnetic beads by sandwich immunoassay. Highly sensitive electrochemical stripping analysis offered a simple and fast method to quantify the captured gold nanoparticle tracers. The stripping signal of gold nanoparticles was found to be proportionally related to the concentration of target IgG in the sample solution [64].

\subsubsection{Physical Adsorption}

Physical adsorption is a convenient and simple procedure for manufacturing biocatalytic sensing devices. It relates to reduce of the gold nanoparticles with a negatively charged ligand such as citrate. The reduced Au nanosized particles in the next step associate with the ligand, insulating the GNPs from electrostatic repulsion and offering it stability. The arising citrate film adds a negative charge onto the colloidal particle surface. Positively charged amino acid residues allow biocatalysts in solution to be electrostatically adsorbed on the surface by hardly dipping the modified electrode into the solution (Figure 5). Though this procedure has the advantage of velocity and simplicity, unfavorable arrangement and decreased functionality are likely [74].

\subsubsection{Chemical Adsorption}

Chemical adsorption causes direct bonding between the biocatalyst and the surface of electrode, i.e. Au surface. There is a transfer or sharing of electron, or breakage of the adsorbate into atoms or radicals which are bound separately. 
Chemical adsorption on gold material is achieved via covalent interaction between the-SH groups of the cysteine residues and gold surface (Figure 6) [75] [76]. Liu et al., associated the merits of self-assembly technique and the strong adsorption properties of-SH/gold to construct a convenient, plain, and fast biocatalytic biosensor for phenols labeling, using tyrosinase [77].

Cyclic voltammetry proved a sigmoidal narrow curve and a wait period of 10 seconds to achieve $95 \%$ of current in steady-state. According to CV measurements, it can be gathered the catalytic current was principally according to the direct electron transport from the active site of protein to the surface of electrode.

One of the recently developed method of immobilization is light-assisted process, that allows to a great control of the biocatalysts' arrangement via thiols (Figure 7). The process is connected with reduction (selective) of disulphide bridges, inside the protein, that are adjoining to aromatic amino acid parts by exposure to UV (270 $300 \mathrm{~nm}$ ). The free-SH groups may then undergo covalent bonding with the Au surface [78]. Snabe et al., immobilized a major histocompatibility complex to a surface of sensing device by light-assisted immobilization [79].

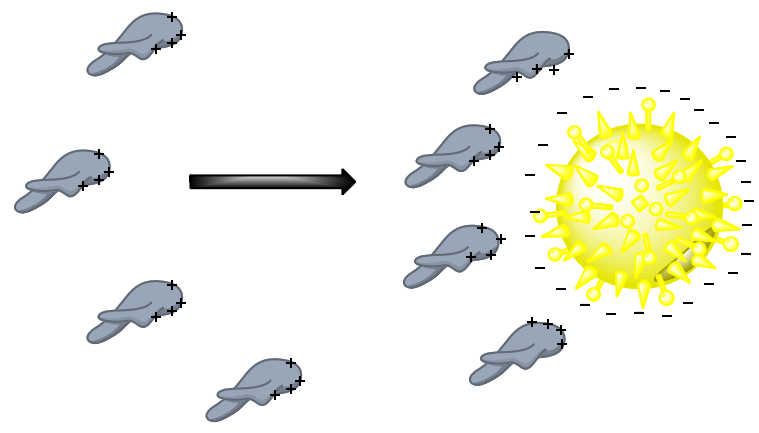

Figure 5. Electrostatic adsorption of biocatalysts directly onto GNPs.

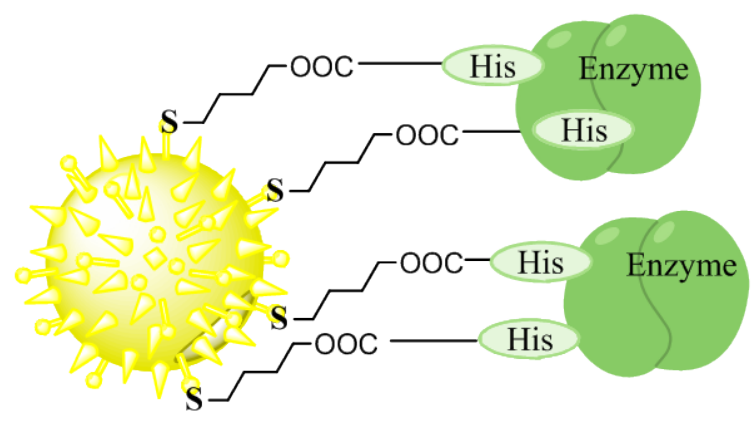

Figure 6. Immobilization of biocatalyst on a gold nanomaterial via chemisorption and covalent attachment.

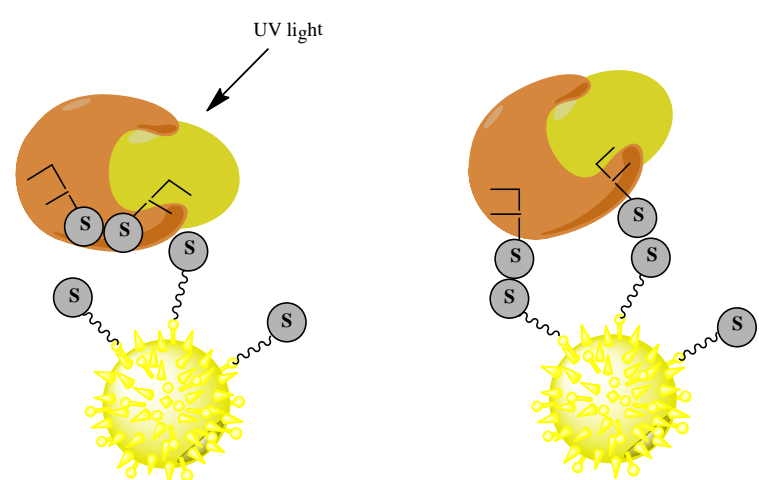

Figure 7. Light-assisted immobilization of bicatalysts onto solid gold support using thiol attachment chemistry. 
Using this procedure, an accurate knowledge of the protein's structure is indispensable. The disulfide bridges have to be in the appropriate place on the molecule to be utilized. Moreover, it should be specified that disulfide degradation will not disrupt the protein's stability or activity.

Subsequent site-oriented covalent procedure is manufactured to obtain a modified biocatalyst with a genetic label. The pathways by which a biocatalyst is genetically changed or tagged are rather complicated. Briefly, the modified enzyme includes artificially attached residues or units that may be placed to a specific area of the enzyme.

By covalent binding to the modified part of the protein, specific arrangement may be reached. The recent studies alter biocatalyst with a metal-binding site, allowing for reorientation. Madoz-Gurpide et al., conducted an immobilization of ferredoxin: $\mathrm{NADP}^{+}$reductase onto gold electrode by leading a genetically modified metal binding site on a specific place of the enzyme surface [80]. The gold electrode was covered with a SAMs monolayer of thiols attached with nitrilotriacetic acid residues in complex with metallic ions. Two heterounits were developed to possess a histidine pair (His- $\mathrm{Y}_{3}$-His) on surface-exposed $\alpha$-helices placed in one of the two protein domains. The two modified enzymes revealed differences in biocatalyst loading in the kinetic data, and in capacity to transport electrons to a mediator covalently appended to the SAMs monolayer.

The formerly mentioned developments regarded enzymatic protein immobilization onto a bulk gold solids. Both presented procedures introduce an effective method for directed immobilization onto such a nanosized solid substrate. Ha et al., in example has shown ability for orientated immobilization onto Au nanoparticles [81]. Esterases with a six-membered histidine or arginine tail permitted for selective immobilization onto gold nanoparticles, with result as increasing biological activity. In case of repeatable bonding of the biocatalyst with an un-restricted direction, GNPs were generated via surface modification with 16-mercaptohexadecanoic acid [81]. The carboxylated Au nanosized particles selectively immobilizing the modified esterases via electrostatic similarity with the modified tails. Although all the esterases (tagged and untagged) inclined to non-specific way of adsorption to the carboxylated gold nanoparticles, the magnitude was definitely dependent on the attendance of proper affinity tag. The catalytic activity of the enzymes was found by monitoring the UV/Vis absorption of $p$-nitrophenol butyrate, which reveals a new band at $400 \mathrm{~nm}$ as it dissociates.

\subsection{GNP-Based Electrochemical Biosensors}

The conductivity properties of GNPs enhance the electron transfer between the active centers of proteins and electrodes and thus they act as electron transfer "electron wires". Natan's group have proved the direct electron transfer between the electrode and the protein by GNPs in 1996 for the first time [82]. They showed the direct, reversible cyclic voltammetry of horse heart cytochrome at 12-nm-diameter modified $\mathrm{SnO}_{2}$ electrode, without any pretreatment or polishing steps. They also found that the nanometer-scale morphology of metals was closely related to the protein electrochemistry. Since then, a series of papers has reported the electron communication between the biocatalysts and electrodes using GNPs (Table 1) [83]-[85].

Willner and co-workers studied the electron transfer turnover rate of a reconstituted bioelectrocatalyst using GNPs [89]. Enzyme electrodes exhibited very fast electron transfer between the enzyme redox center and the electrode in the presence of the gold nanoparticles. The electron transfer rate was found to be about 5000 per second, while the rate between glucose oxidase.

GNPs dispersed in polymeric matrices are also used to construct electrochemical biosensors with increased stability, improved processability, reusability and solubility in a variety of solvents [90]. The nanocomposite of GNPs and biopolymer, such as chitosan and poly (p-aminobenzene sulfonic acid) has been employed as an excellent matrix for fabricating novel biosensors [90].

Table 1. Electrochemical biosensor including GNPs.

\begin{tabular}{cccccc}
\hline Enzyme & Method of immobilization & Substrate & Detection limit & Sensitivity & References \\
\hline $\begin{array}{c}\text { Horseradish } \\
\text { peroxidase }\end{array}$ & Covalent attachment to GNPs & $\mathrm{H}_{2} \mathrm{O}_{2}$ & $2.0 \mu \mathrm{M}$ & - & Jia J. et al. [86] \\
$\begin{array}{c}\text { Tyrosinase } \\
\text { Glucose oxidase }\end{array}$ & Chemical adsorption on GNPs & Catechol & $0.06 \mu \mathrm{M}$ & $3.94 \mathrm{~mA} / \mathrm{mM} \cdot \mathrm{cm}^{2}$ & Liu Z. et al. [78] \\
$\begin{array}{c}\text { Clucose oxidase } \\
\text { Covalent attachment to multilayer }\end{array}$ & Glucose & - & $5.72 \mathrm{~mA} / \mathrm{mM} \cdot \mathrm{cm}^{2}$ & Yang W. et al. [87] \\
\hline
\end{tabular}


The GNPs offer excellent candidates for the immobilization platform. The adsorption of biomolecules onto the surfaces of GNPs can retain their bioactivity and stability because of the biocompatibility and the high surface free energy of GNPs [91]. GNPs, as compared with flat gold surfaces, have a much higher surface area, allowing loading of a larger amount of protein and are potentially more sensitive. Thus, a number of labs have explored the contribution of GNPs for biomolecular immobilization [92].

A recent research reported by Tuener et al. [93] has studied the effect of GNPs' diameter and supported material on the catalytic activity of GNPs. They showed that very small gold entities $(\sim 1.4 \mathrm{~nm})$ derived from 55-atom gold clusters and support materials are efficient and robust catalysts for the selective oxidation of styrene by dioxygen. A sharp size threshold in catalytic activity, where particles with diameters of $2 \mathrm{~nm}$ and above are completely inactive, was also determined. Their observations suggested that catalytic activity arises from the altered electronic structure intrinsic to small gold nanoparticles.

\section{Summary and Future Trends}

Electrochemical nanobiosensors offer without doubts an important step toward development of selective, down to few target molecules sensitive biorecognition device for medical and security applications. In their case, very high amplification of signal could be reached, i.e. using high diameter carbon nanotubes filled with nanoparticles and their following electrochemical stripping.

The utilization of nano-manipulation techniques has also become an interesting approach to fabricate electrochemical devices with high specificity and molecular order. Moreover, the sensitivity and overall behavior of biosensors has grown rapidly as an outcome of incorporating different nanomaterials in their construction.

Electrochemical nanobiosensors consisting from single carbon nanotube are clear examples of future path of biosensor development. These strategies waits for exploration. There is high expectation that such devices will develop toward reliable point-of-care diagnostics of cancer and other diseases, and as tools for intra-operation pathological testing, proteomics and systems biology.

\section{Acknowledgements}

Authors are gratefully acknowledged for financial support of NCN-Grant no. 2012/05/B/ST5/00749 and Wrocław University of Technology.

\section{References}

[1] Luo, X., Morrin, A., Killard, A.J. and Smyth, M.R. (2006) Application of Nanoparticles in Electrochemical Sensors and Biosensors. Electroanalysis, 18, 319-326. http://dx.doi.org/10.1002/elan.200503415

[2] Dukhin, A.S. and Dukhin, S.S. (2005) Aperiodic Capillary Electrophoresis Method Using an Alternating Current Electric Field for Separation of Macromolecules. Electrophoresis, 26, 2149-2153. http://dx.doi.org/10.1002/elps.200410408

[3] Sheldon, R.A. and van Pelt, S. (2013) Enzyme Immobilisation in Biocatalysis: Why, What and How. Chemical Society Reviews, 42, 6223-6235. http://dx.doi.org/10.1039/c3cs60075k

[4] Amman, M. (2014) Electrochemical and Electrophoretic Deposition of Enzymes: Principles, Differences and Application in Miniaturized Biosensor and Biofuel Cell Electrodes. Biosensors and Bioelectronics, 58, 121-131. http://dx.doi.org/10.1016/j.bios.2014.02.030

[5] Ammam, M. and Fransaer, J. (2009) AC-Electrophoretic Deposition of Glucose Oxidase. Biosensors and Bioelectronics, 25, 191-197. http://dx.doi.org/10.1016/j.bios.2009.06.036

[6] Wang, S.S. and Vieth, W.R. (1973) Immobilization of Whole Cells in a Membraneous Form. Biotechnology and Bioengineering, 15, 93-115. http://dx.doi.org/10.1002/bit.260150108

[7] Johnston, D.A., Cardosi, M.F. and Vaughan, D.H. (1995) The Electrochemistry of Hydrogen Peroxide on Evaporated Gold/Palladium Composite Electrodes. Manufacture and Electrochemical Characterization. Electroanalysis, 7, 520526. http://dx.doi.org/10.1002/elan.1140070603

[8] Gao, Z.Q., Binyamin, G., Kim, H.H., Barton, S.C., Zhang, Y.C. and Heller, A. (2002) Electrodeposition of Redox Polymers and Co-Electrodeposition of Enzymes by Coordinative Crosslinking. Angewandte Chemie International Edition, 41, 810-813. http://dx.doi.org/10.1002/1521-3773(20020301)41:5<810::AID-ANIE810>3.0.CO;2-I

[9] Ackermann, Y., Guschin, D.A., Eckhard, K., Shleev, S. and Schuhmann, W. (2010) Design of a Bioelectrocatalytic Electrode Interface for Oxygen Reduction in Biofuel Cells Based on a Specifically Adapted Os-Complex Containing 
Redox Polymer with Entrapped Trametes Hirsuta Laccase. Electrochemistry Communications, 12, 640-643. http://dx.doi.org/10.1016/j.elecom.2010.02.019

[10] Chiu, J.Y., Yu, C.M., Yen, M.J. and Chen, L.C. (2009) Glucose Sensing Electrodes Based on a Poly(3,4-Ethylenedioxythiophene)/Prussian Blue Bilayer and Multi-Walled Carbon Nanotubes. Biosensors and Bioelectronics, 24, 20152020. http://dx.doi.org/10.1016/j.bios.2008.10.010

[11] Almeida, N.F., Beckman, E.J. and Ataai, M.M. (1993) Immobilization of Glucose Oxidase in Thin Polypyrrole Films: Influence of Polymerization Conditions and Film Thickness on the Activity and Stability of the Immobilized Enzyme. Biotechnology and Bioengineering, 42, 1037-1045. http://dx.doi.org/10.1002/bit.260420904

[12] Matsumoto, N., Chen, X.H. and Wilson, G.S. (2002) Fundamental Studies of Glucose Oxidase Deposition on a Pt Electrode. Analytical Chemistry, 74, 362-367. http://dx.doi.org/10.1021/ac015536x

[13] Iwuoha, E.I., Saenzde Villaverde, D., Garcia, N.P., Smyth, M.R. and Pingarron, J.M. (1997) Reactivities of Organic Phase Biosensors. 2. The Amperometric Behaviour of Horseradish Peroxidase Immobilised on a Platinum Electrode Modified with an Electrosynthetic Polyaniline Film. Biosensors and Bioelectronics, 12, 749-761. http://dx.doi.org/10.1016/S0956-5663(97)00042-0

[14] Vidal, J.C., Garcia, E. and Castillo, J.R. (1999) In Situ Preparation of Overoxidized PPy/oPPD Bilayer Biosensors for the Determination of Glucose and Cholesterol in Serum. Sensors and Actuators B, 57, 219-226. http://dx.doi.org/10.1016/S0925-4005(99)00082-9

[15] Ammam, M. and Fransaer, J. (2010) Alternating Current Electrophoretic Deposition of Saccharomyces cerevisiae Cells and the Viability of the Deposited Biofilm in Ethanol Production. Electrochimica Acta, 55, 9125-9131.

[16] Ammam, M. and Fransaer, J. (2011) Effects of AC-Electrolysis on the Enzymatic Activity of Glucose Oxidase. Electroanalysis, 23, 755-763.

[17] Ammam, M. and Fransaer, J. (2010) Micro-Biofuel Cell Powered by Glucose/ $\mathrm{O}_{2}$ Based on Electro-Deposition of Enzyme, Conducting Polymer and Redox Mediators: Preparation, Characterization and Performance in Human Serum. Biosensors and Bioelectronics, 25, 1474-1480. http://dx.doi.org/10.1016/j.bios.2009.11.001

[18] Schnorr, J.M. and Swager, T.M. (2011) Emerging Applications of Carbon Nanotubes. Chemistry of Materials, 23, 646657. http://dx.doi.org/10.1021/cm102406h

[19] Baughman, R.H., Zakhidov, A.A. and de Heer, W.A. (2002) Carbon Nanotubes-The Route toward Applications. Science, 297, 787-792. http://dx.doi.org/10.1126/science.1060928

[20] Hrapovic, S., Liu, Y., Male, K.B. and Luong, J.H.T. (2004) Electrochemical Biosensing Platform Using Platinum Nanopartyicles and Carbon Nanotubes. Analytical Chemistry, 76, 1083-1088. http://dx.doi.org/10.1021/ac035143t

[21] Girard-Egrot, A.P., Godoy, S. and Blum, L.J. (2005) Enzyme Association with Lipidic Langmuir-Blodgett Films: Interests and Applications in Nanobioscience. Advances in Colloid and Interface Science, 116, 205-225. http://dx.doi.org/10.1016/j.cis.2005.04.006

[22] Caseli, L., Moraes, M.L., Zucolotto, V., Ferreira, M., Nobret, T.M., Zaniquelli, M.E.D., Pereira, U. and Oliveira Jr., O.N. (2006) Fabrication of Phytic Acid Sensor Based on Mixed Phytase-Lipid Langmuir-Blodgett Films. Langmuir, 22, 8501-8508. http://dx.doi.org/10.1021/la061799g

[23] Schmidt, T.F., Caseli, L., Viitala, T. and Oliveira Jr., O.N. (2008) Enhanced Activity of Horseradish Peroxidase in Langmuir-Blodgett Films of Phospholipids. Biochimica et Biophysica Acta, 1778, 2291-2297. http://dx.doi.org/10.1016/j.bbamem.2008.05.012

[24] Yin, F., Kafi, A.K.M., Shin, H.K. and Kwon, Y.S. (2005) Human Serum Albumin-Octadecylamine Langmuir-Blodgett Film Formed by Spreading Human Serum Albumin Solution Directly on Subphase's Interface Covered with a Layer of Octadecylamine. Thin Solid Films, 488, 223-229. http://dx.doi.org/10.1016/j.tsf.2005.04.030

[25] Caseli, L., Nobre, T.M., Zaniquelli, M.E.D., Zucolotto, V. and Oliveira Jr., O.N. (2008) Using Phospholipid Langmuir and Langmuir-Blodgett Films as Matrix for Urease Immobilization. Journal of Colloid and Interface Science, 319, 100-108. http://dx.doi.org/10.1016/j.jcis.2007.12.007

[26] Apetrei, C., Alessio, P., Constantino, C.J.L., de Saja, J.A., Rodriguez-Mendez, M.L., Pavinatto, F.J., Fernandes, E.G.R., Zucolotto, V. and Oliveira Jr., O.N. (2011) Biomimetic Biosensor Based on Lipidic Layers Containing Tyrosinase and Lutetium Bisphthalocyanine for the Detection of Antioxidants. Biosensors and Bioelectronics, 26, 2513-2519. http://dx.doi.org/10.1016/j.bios.2010.10.047

[27] Cabaj, J., Chyla, A., Jędrychowska, A., Olech, K. and Sołoducho, J. (2012) Detecting Platform for Phenolic Compounds-Characteristic of Enzymatic Electrode. Optical Materials, 34, 1677-1681. http://dx.doi.org/10.1016/j.optmat.2012.02.042

[28] Sun, Q., Zorin, N.A., Chen, D., Chen, M., Lieu, T.X., Myake, J. and Qian, D.J. (2010) Langmuir-Blodgett Films of Pyridyldithio-Modified Multiwalled Carbon Nanotubes as a Support to Immobilize Hydrogenase. Langmuir, 26, 10259-10265. http://dx.doi.org/10.1021/la100432t 
[29] Decher, G. and Hong, J.D. (1991) Buildup of Ultrathin Multilayer Films by a Self-Assembly Process: II. Consecutive Adsorption of Anionic and Cationic Bipolar Amphiphiles and Polyelectrolytes on Charged Surfaces. Berichte der Bunsengesellschaft für physikalische Chemie, 95, 1430-1434. http://dx.doi.org/10.1002/bbpc.19910951122

[30] Decher, G. (1997) Fuzzy Nanoassemblies: Toward Layered Polymeric Multicomposites. Science, 277, 1232-1237. http://dx.doi.org/10.1126/science.277.5330.1232

[31] Siqueira Jr., J.R., Gasparoto, L.H.S., Crespilho, F.N., Carvalho, A.J.F., Zucolotto, V. and Oliveira Jr., O.N. (2006) Physicochemical Properties and Sensing Ability of Metallophthalocyanines/Chitosan Nanocomposites. Journal of Physical Chemistry B, 110, 22690-22694. http://dx.doi.org/10.1021/jp0649089

[32] Jeong, R.A., Hwang, J.Y., Joo, S., Chung, T.D., Vark, S.P., Kang, S.K., Lee, W.Y. and Kim, H.C. (2003) In Vivo Calibration of the Subcutaneous Amperometric Glucose Sensors Using a Non-Enzyme Electrode. Biosensors and Bioelectronics, 19, 313-319. http://dx.doi.org/10.1016/S0956-5663(03)00219-7

[33] Jie, G., Liu, B., Pan, H., Zhu, J.J. and Chen, H.Y. (2007) CdS Nanocrystal-Based Electrochemiluminescence Biosensor for the Detection of Low-Density Lipoprotein by Increasing Sensitivity with Gold Nanoparticle Amplification. Analytical Chemistry, 79, 5574-5581. http://dx.doi.org/10.1021/ac062357c

[34] Shi, G.Y., Qu, Y.H., Zhai, Y.Y., Liu, Y., Sun, Z.Y., Yang, J.G. and Jin, L.T. (2007) \{MSU/PDDA $\}_{n}$ LBL Assembled Modified Sensor for Electrochemical Detection of Ultratrace Explosive Nitroaromatic Compounds. Electrochemistry Communications, 9, 1719-1724. http://dx.doi.org/10.1016/j.elecom.2007.03.019

[35] Hou, Y., Cheng, Y., Hobson, T. and Liu, J. (2010) Design and Synthesis of Hierarchical $\mathrm{MnO}_{2}$ Nanospheres/Carbon Nanotubes/Conducting Polymer Ternary Composite for High Performance Electrochemical Electrodes. Nano Letters, 10, 2727-2733. http://dx.doi.org/10.1021/nl101723g

[36] Cassier, T., Lowack, K. and Decher, G. (1998) Layer-by-Layer Assembled Protein/Polymer Hybrid Films: Nasnoconstruction via Specific Recognition. Supramolecular Science, 5, 309-315. http://dx.doi.org/10.1016/S0968-5677(98)00024-8

[37] Ram, K., Bertoncello, M.P., Ding, H., Paddeu, S. and Nicolini, C. (2001) Cholesterol Biosensors Prepared by Layerby-Layer Technique. Biosensors and Bioelectronics, 16, 849-856. http://dx.doi.org/10.1016/S0956-5663(01)00208-1

[38] Musameh, M., Wang, J., Merkoci, A. and Lin, Y.H. (2002) Low-Potential Stable NADH Detection at Carbon-NanotubeModified Glassy Carbon Electrodes. Electrochemistry Communications, 4, 743-746. http://dx.doi.org/10.1016/S1388-2481(02)00451-4

[39] Dequaire, M., Degrand, C. and Limoges, B. (2000) An Electrochemical Metalloimmunoassay Based on a Colloidal Gold Label. Analytical Chemistry, 72, 5521-5528. http://dx.doi.org/10.1021/ac000781m

[40] Sadik, O.A., Aluoch, A.O. and Zhou, A.L. (2009) Status of Biomolecular Recognition Using Electrochemical Techniques. Biosensors and Bioelectronics, 24, 2749-2765. http://dx.doi.org/10.1016/j.bios.2008.10.003

[41] Zhang, S., Wang, N., Yu, H., Niu, Y. and Sun, C. (2005) Tailoring the Surface Potential of Gold Nanoparticles with Self-Assembled Monolayers with Mixed Functional Groups. Biochemistry, 67, 15-22.

[42] Yogeswaran, U. and Chen, S.M. (2008) A Review on the Electrochemical Sensors and Biosensors Composed of Nanowires as Sensing Material. Sensors, 8, 290-313. http://dx.doi.org/10.3390/s8010290

[43] Ajayan, P.M. (1999) Nanotubes from Carbon. Chemical Reviews, 99, 1787-1800. http://dx.doi.org/10.1021/cr970102g

[44] Lynam, C., Gilmartin, N., Minett, A.I., O’Kennedy, R. and Wallace, G. (2009) Carbon Nanotube-Based Transducers for Immunoassays. Carbon, 47, 2337-2343. http://dx.doi.org/10.1016/j.carbon.2009.04.017

[45] Zhao, Y.D., Zhang, W.D., Chen, H., Luo, Q.F. and Li, S.F.Y. (2002) Direct Electrochemistry of Horseradish Peroxidase at Carbon Nanotube Powder Microelectrode. Sensors and Actuators B, 87, 168-172. http://dx.doi.org/10.1016/S0925-4005(02)00232-0

[46] Yamamoto, K., Shi, G., Zhou, T.S., Xu, F., Xu, J.M., Kato, T., Jind, J.Y. and Jin, L.T. (2003) Study of Carbon Nanotubes-HRP Modified Electrode and Its Application for Novel On-Line Biosensors. Analyst, 128, 249-254. http://dx.doi.org/10.1039/b209698f

[47] Wang, J.X., Li, M.X., Shi, Z.J., Li, N.Q. and Gu, Z.N. (2002) Direct Electrochemistry of Cytochrome $c$ at a Glassy Carbon Electrode Modified with Single-Wall Carbon Nanotubes. Analytical Chemistry, 74, 1993-1997. http://dx.doi.org/10.1021/ac010978u

[48] Davis, J.J., Coles, R.J., Allen, H. and Hill, O. (1997) Protein Electrochemistry at Carbon Nanotube Electrodes. Journal of Electroanalytical Chemistry, 440, 279-282.

[49] Guiseppi-Elie, A., Lei, C.H. and Baughman, R.H. (2002) Direct Electron Transfer of Glucose Oxidase on Carbon Nanotubes. Nanotechnology, 13, 559-564. http://dx.doi.org/10.1088/0957-4484/13/5/303

[50] Dechakiatkrai, C., Chen, J., Lynam, C., Min, S.K., Kim, S.J., Phanichphant, S. and Wallace, G.G. (2008) Direct Ascorbic Acid Detection with Ferritin Immobilized on Single-Walled Carbon Nanotubes. Electrochemical and Solid- 
State Letters, 11, K4-K6. http://dx.doi.org/10.1149/1.2795834

[51] Chen, R.J., Zhang, Y.G., Wang, D.W. and Dai, H.J. (2001) Noncovalent Sidewall Functionalization of Single-Walled Carbon Nanotubes for Protein Immobilization. Journal of the American Chemical Society, 123, 3838-3839. http://dx.doi.org/10.1021/ja010172b

[52] Rubianes, M.D. and Rivas, G.A. (2003) Carbon Nanotubes Paste Electrode. Electrochemistry Communications, 5, 689694. http://dx.doi.org/10.1016/S1388-2481(03)00168-1

[53] Perez, B., Pumera, M., del Valle, M., Merkoci, A. and Alegret, S. (2005) Glucose Biosensor Based on Carbon Nanotube Epoxy Composites. Journal of Nanoscience and Nanotechnology, 5, 1694-1698. http://dx.doi.org/10.1166/jnn.2005.400

[54] Pumera, M., Merkoci, A. and Alegret, S. (2006) Carbon Nanotube-Epoxy Composites for Electrochemical Sensing. Sensors and Actuators B, 113, 617-622. http://dx.doi.org/10.1016/j.snb.2005.07.010

[55] Wang, J. and Musameh, M. (2004) Carbon Nanotube Screen-Printed Electrochemical Sensors. Analyst, 129, 1-2. http://dx.doi.org/10.1039/b313431h

[56] Sanchez, S., Pumera, M., Cabruja, E. and Fabregas, E. (2007) Carbon Nanotube/Polysulfone Composite Screen-Printed Electrochemical Enzyme Biosensors. Analyst, 132, 142-147. http://dx.doi.org/10.1039/b609137g

[57] Armada, M.P.G., Losada, J., Cuadrado, I., Alonso, B., Gonzalez, B., Casado, C.M. and Zhang, J.B. (2004) Preparation of Biosensors Based in a Siloxane Homopolymer with Interacting Ferrocenes for the Amperometric Detection of Peroxides. Sensors and Actuators B, 101, 143-149. http://dx.doi.org/10.1016/j.snb.2004.02.043

[58] Liu, G.D. and Lin, Y.H. (2006) Amperometric Glucose Biosensor Based on Self-Assembling Glucose Oxidase on Carbon Nanotubes. Electrochemistry Communications, 8, 251-256. http://dx.doi.org/10.1016/j.elecom.2005.11.015

[59] Liu, G.D. and Lin, Y.H. (2006) Carbon Nanotube-Templated Assembly of Protein. Journal of Nanoscience and Nanotechnology, 6, 948-953. http://dx.doi.org/10.1166/jnn.2006.133

[60] Qu, F.L., Yang, M.H., Jiang, J.H., Shen, G.L. and Yu, R.Q. (2005) Amperometric Biosensor for Choline Based on Layer-by-Layer Assembled Functionalized Carbon Nanotube and Polyaniline Multilayer Film. Analytical Biochemistry, 344, 108-114. http://dx.doi.org/10.1016/j.ab.2005.06.007

[61] Zhao, H.T. and Ju, H.X. (2006) Multilayer Membranes for Glucose Biosensing via Layer-by-Layer Assembly of Multiwall Carbon Nanotubes and Glucose Oxidase. Analytical Biochemistry, 350, 138-144. http://dx.doi.org/10.1016/j.ab.2005.11.034

[62] Yu, X., Chattopadhyay, D., Galeska, I., Papadimitrakopoulos, F. and Rusling, J.F. (2003) Peroxidase Activity of Enzymes Bound to the Ends of Single-Wall Carbon Nanotube Forest Electrodes. Electrochemistry Communications, 5, 408-411. http://dx.doi.org/10.1016/S1388-2481(03)00076-6

[63] Patolsky, F., Weizmann, Y. and Willner, I. (2004) Long-Range Electrical Contacting of Redox Enzymes by SWCNT Connectors. Angewandte Chemie International Edition, 43, 2113-2117. http://dx.doi.org/10.1002/anie.200353275

[64] Pumera, M., Sanchez, S., Ichinose, I. and Tang, J. (2007) Electrochemical Nanobiosensors. Sensors and Actuators B, 123, 1195-1205. http://dx.doi.org/10.1016/j.snb.2006.11.016

[65] Cui, Y., Wei, Q.Q., Park, H.K. and Lieber, C.M. (2001) Functional Nanoscale Electronic Devices Assembled Using Silicon Nanowire Building Blocks. Science, 293, 1289-1292.

[66] Zhou, X.T., Hu, J.Q., Li, C.P., Ma, D.D.D., Lee, C.S. and Lee, S.T. (2003) Silicon Nanowires as Chemical Sensors. Chemical Physics Letters, 369, 220-224. http://dx.doi.org/10.1016/S0009-2614(02)02008-0

[67] Shao, M.W., Yao, H., Zhang, M.L., Wong, N.B., Shan, Y.Y. and Lee, S.T. (2005) Fabrication and Application of Long Strands of Silicon Nanowires as Sensors for Bovine Serum Albumin Detection. Applied Physics Letters, 87, Article ID: 183106. http://dx.doi.org/10.1063/1.2123393

[68] Shao, M.W., Shan, Y.Y., Wong, N.B. and Lee, S.T. (2005) Silicon Nanowire Sensors for Bioanalytical Application: Glucose and Hydrogen Peroxide Detectionadv. Advanced Functional Materials, 15, 1478-1482. http://dx.doi.org/10.1002/adfm.200500080

[69] Janata, J. and Blackburn, G.F. (1984) Immunochemical Potentiometric Sensors. Annals of the New York Academy of Sciences, 428, 286-292. http://dx.doi.org/10.1111/j.1749-6632.1984.tb12304.x

[70] Janata, J. (1989) Principles of Chemical Sensors. Plenum Press, New York.

[71] Klabunde, K.J. (2001) Introduction to Nanotechnology. In: Klabunde, K.J., Ed., Nanoscale Materials in Chemistry, John Wiley and Sons, New York.

[72] Du, J., Yu, X.P. and Di, J.W. (2012) Comparison of the Direct Electrochemistry of Glucose Oxidase Immobilized on the Surface of $\mathrm{Au}, \mathrm{CdS}$ and ZnS Nanostructures. Biosensors and Bioelectronics, 37, 88-93. http://dx.doi.org/10.1016/j.bios.2012.04.044 
[73] Zheng, B.Z., Xie, S.P., Qian, L., Yuan, H.Y., Xiao, D. and Choi, M.M.F. (2011) Gold Nanoparticles-Coated Eggshell Membrane with Immobilized Glucose Oxidase for Fabrication of Glucose Biosensor. Sensors and Actuators B, 152, 49-55. http://dx.doi.org/10.1016/j.snb.2010.09.051

[74] Hanefeld, U., Gardossi, L. and Magner, E. (2009) Understanding Enzyme Immobilization. Chemical Society Reviews, 38, 453-468. http://dx.doi.org/10.1039/b711564b

[75] Brogan, K.L., Wolfe, K.N., Jones, P.A. and Schoenfisch, M.H. (2003) Direct Oriented Immobilization of F(ab’) Antibody Fragments on Gold. Analytica Chimica Acta, 496, 73-80. http://dx.doi.org/10.1016/S0003-2670(03)00991-7

[76] Rao, S.V., Anderson, K.W. and Bachas, L.G. (1998) Fundamental Review, Oriented Immobilization of Proteins. Microchimica Acta, 128, 127-143. http://dx.doi.org/10.1007/BF01243043

[77] Liu, Z.M., Liu, J., Shen, G.L. and Yu, R.Q. (2006) A Reagentless Tyrosinase Biosensor Based on 1,6-Hexanedithiol and Nano-Au Self-Assembled Monolayers. Electroanalysis, 18, 1572-1577. http://dx.doi.org/10.1002/elan.200603512

[78] Nakanishi, K., Sakiyama, T., Kumada, Y., Immamura, K. and Imanaka, H. (2008) Recent Advances in Controlled Immobilization of Proteins onto the Surface of the Solid Substrate and Its Possible Application to Proteomics. Current Proteomics, 5, 161-175. http://dx.doi.org/10.2174/157016408785909622

[79] Snabe, T., Rode, G.A., Neves-Petersen, M.T., Buus, S. and Petersen, S.B. (2006) Oriented Coupling of Major Histocompatibility Complex (MHC) to Sensor Surfaces Using Light Assisted Immobilization Technology. Biosensors and Bioelectronics, 21, 1553-1559. http://dx.doi.org/10.1016/j.bios.2005.06.010

[80] Madoz-Gúrpide, J., Abad, J.M., Fernández-Recio, J., Vélez, M., Vázquez, L., Gómez-Moreno, C. and Fernández, V.M. (2000) Modulation of Electroenzymatic NADPH Oxidation through Oriented Immobilization of Ferredoxin: NADP ${ }^{+}$ Reductase onto Modified Gold Electrodes. Journal of the American Chemical Society, 122, 9808-9817. http://dx.doi.org/10.1021/ja001365m

[81] Ha, T.H., Jeong, J.Y. and Chung, B.H. (2005) Immobilization of Hexa-Arginine Tagged Esterase onto Carboxylated Gold Nanoparticles. Chemical Communications, 48, 3959-3961. http://dx.doi.org/10.1039/b504184h

[82] Brown, K.R., Fox, A.P. and Natan, M.J. (1996) Morphology-Dependent Electrochemistry of Cytochrome $c$ at Au Colloid-Modified $\mathrm{SnO}_{2}$ Electrodes. Journal of the American Chemical Society, 118, 1154-1157. http://dx.doi.org/10.1021/ja952951w

[83] Lin, J., Qu, W. and Zhang, S. (2007) Disposable Biosensor Based on Enzyme Immobilized on Au-Chitosan-Modified Indium Tin Oxide Electrode with Flow Injection Amperometric Analysis. Analytical Biochemistry, 360, 288-293. http://dx.doi.org/10.1016/j.ab.2006.10.030

[84] Tangkuaram, T., Ponchio, C., Kangkasomboon, T., Katikawong, P. and Veerasai, W. (2007) Design and Development of a Highly Stable Hydrogen Peroxide Biosensor on Screen Printed Carbon Electrode Based on Horseradish Peroxidase Bound with Gold Nanoparticles in the Matrix of Chitosan. Biosensors and Bioelectronics, 22, 2071-2078. http://dx.doi.org/10.1016/j.bios.2006.09.011

[85] Shumyantseva, V.V., Carrara, S., Bavastrello, V., Jason Riley, D., Bulko, T.V., Skryabin, K.G., Archakov, A.I. and Nicolini, C. (2005) Direct Electron Transfer between Cytochrome P450scc and Gold Nanoparticles on Screen-Printed Rhodium-Graphite Electrodes. Biosensors and Bioelectronics, 21, 217-222. http://dx.doi.org/10.1016/j.bios.2004.10.008

[86] Abad, J.M., Velez, M., Santamaria, C., Guisan, J.M., Matheus, P.R., Vazquez, L., Gazaryan, I., Gorton, L., Gibson, T. and Fernandez, V.M. (2002) Immobilization of Peroxidase Glycoprotein on Gold Electrodes Modified with Mixed Epoxy-Boronic Acid Monolayers. Journal of the American Chemical Society, 124, 12845-12853. http://dx.doi.org/10.1021/ja026658p

[87] Challa, S.S.R.K. (2010) Nanocomposites: Nanomaterials for the Life Sciences. Wiley-VCH, Weinheim.

[88] Yang, W.W., Wang, J.X., Zhao, S., Sun, Y.Y. and Sun, C.Q. (2006) Multilayered Construction of Glucose Oxidase and Gold Nanoparticles on Au Electrodes Based on Layer-by-Layer Covalent Attachment. Electrochemistry Communications, 8, 665-672. http://dx.doi.org/10.1016/j.elecom.2005.11.014

[89] Xiao, Y., Patolsky, F., Katz, E., Hainfeld, J.F. and Willner, I. (2003) “Plugging into Enzymes”: Nanowiring of Redox Enzymes by a Gold Nanoparticle. Science, 299, 1877-1881. http://dx.doi.org/10.1126/science.1080664

[90] Gao, F.X., Yuan, R., Chai, Y.Q., Chen, S.H., Cao, S.R. and Tang, M.Y. (2007) Amperometric Hydrogen Peroxide Biosensor Based on the Immobilization of HRP on Nano-Au/Thi/Poly ( $p$-Aminobenzene Sulfonic Acid)-Modified Glassy Carbon Electrode. Journal of Biochemical and Biophysical Methods, 70, 407-413. http://dx.doi.org/10.1016/j.jbbm.2006.09.007

[91] Yang, G., Yuan, R. and Chai, Y.Q. (2008) A High-Sensitive Amperometric Hydrogen Peroxide Biosensor Based on the Immobilization of Hemoglobin on Gold Colloid/L-Cysteine/Gold Colloid/Nanoparticles Pt-Chitosan Composite Film-Modified Platinum Disk Electrode. Colloids and Surfaces B, 61, 93-100. http://dx.doi.org/10.1016/j.colsurfb.2007.07.014 
[92] Tang, L., Zeng, G.M., Shen, G.L., Li, Y.P., Zhang, Y. and Huang, D.L. (2008) Rapid Detection of Picloram in Agricultural Field Samples Using a Disposable Immunomembrane-Based Electrochemical Sensor. Environmental Science \& Technology, 42, 1207-1212. http://dx.doi.org/10.1021/es7024593

[93] Turner, M., Golovko, V.B., Vaughan, O.P., Abdulkin, P., Berenguer-Murcia, A., Tikhov, M.S., Johnson, B.F. and Lambert, R.M. (2008) Selective Oxidation with Dioxygen by Gold Nanoparticle Catalysts Derived from 55-Atom Clusters. Nature, 454, 981-983. http://dx.doi.org/10.1038/nature07194 
Scientific Research Publishing (SCIRP) is one of the largest Open Access journal publishers. It is currently publishing more than 200 open access, online, peer-reviewed journals covering a wide range of academic disciplines. SCIRP serves the worldwide academic communities and contributes to the progress and application of science with its publication.

Other selected journals from SCIRP are listed as below. Submit your manuscript to us via either submit@scirp.org or Online Submission Portal.
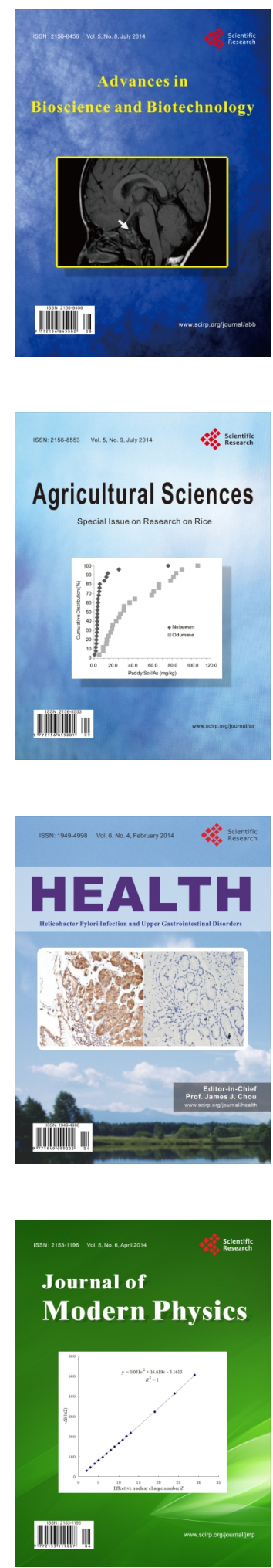
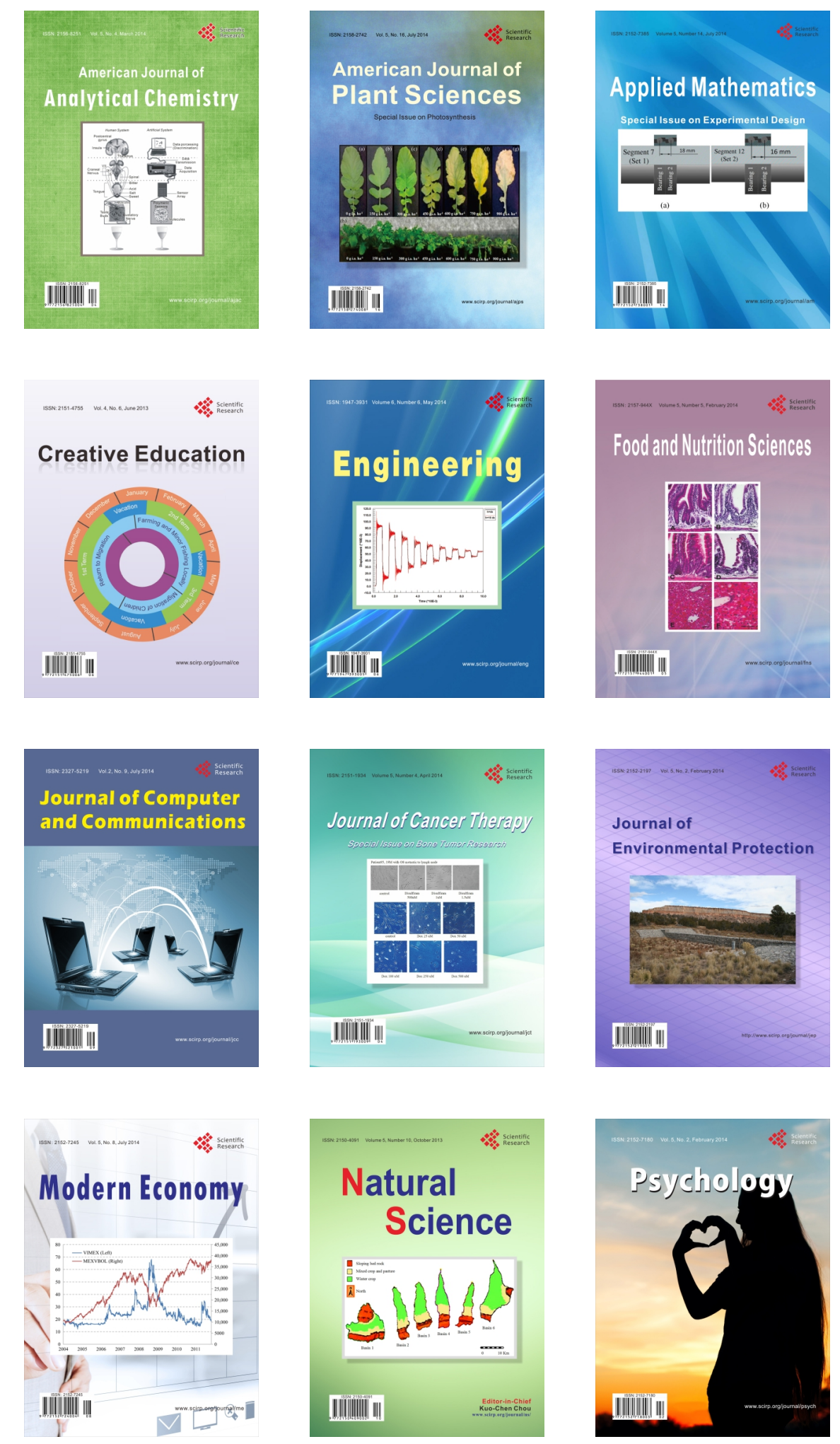